\title{
Fermentative Processing of Kinnow Juice and Extraction of Limonin from Kinnow Waste
}

\author{
Kusum Dua and Gurvinder Singh Kocher* \\ Department of Microbiology, Punjab Agricultural University, India
}

Submission: May 01, 2017; Published: May 23, 2017

"Corresponding author: Gurvinder Singh Kocher, Department of Microbiology, Punjab Agricultural University, Ludhiana, India, Email: gskocher@pau.edu

\section{Opinion}

Kinnow, a hybrid of Citrus nobilis and Citrus delicosa is presently the primary citrus crop of Punjab with annual production of 1.1 million tonnes from an area of 48000 hectare (Punjab Horticulture Mission 2015-16). The fruits are juicy and the fresh juice extracted from the fruit harvested at appropriate stage of maturity, has refreshing flavour, characteristic pleasing aroma and thirst quenching properties. Kinnow fruit is also marked with the problem of short post-harvest shelf life which can be extended to a maximum period of up to 45 days under refrigerated storage conditions [1]. In view of its high production and limited shelf life, the fruit needs to be processed so as to extend its availability and also minimize its glut in the market during peak season of production.

It has been reported that fermentation plays an important role in preserving quality of the fruit juice. This can also solve the problems of over production and related spoilage, apart from development of a new variety of wine. Wines, the alcoholic beverages have witnessed several reports on their beneficial effects on the cardiovascular system as well as the general well being of the consumers [2]. Biochemically, wine consists of water, alcohol, pigments, esters, vitamins, carbohydrates, minerals, acids, and tannins with medicinal and therapeutic value [3]. However till date, only a little work has been reported for the development of kinnow-wines but it has been indicated that direct fermentation of kinnow mandarin juice yields bitterness in the wine. Researchers have though investigated preparation of cane juice blended kinnow-wine without debittering the kinnow juice [4]. Bhardwaj \& Mukherjee [1] have also reported improvement in the taste, aroma, palatability, nutritive value and reduced bitterness of kinnow juice when blended with highly nutritive fruit juices namely Pomegranate and Aonla juice along with spice extracts like ginger juice. Joshi et al. [50] also prepared and evaluated wines from different citrus fruits viz; mandarin, orange, kinnow and galgal. They reported kinnow wine to have maximum fermentation rate (1.52) and ethanol production (12.20\%) among other citrus wines with persistence of bitterness.

Keeping in mind the increasing need of kinnow juice fermentative processing, we blended kinnow juice $(60 \%$ recovery) and date (Phoenix dactylifera) paste to prepare a Kinnow-Date wine. Fermentation was initiated with pectinase treated juice of fresh dates with initial TSS $20{ }^{\circ} \mathrm{B}$, total acidity- $0.75 \%$ (Table 1). Active yeast culture of Saccharomyces cerevisiae MTCC-11815 was pitched @ 7\% and the juice was allowed to ferment along with incremental addition of kinnow juice along with date paste so as to raise the brix (Figure 1). It was scaled up to $7 \mathrm{~L}$ having kinnow and date juice in the ratio of $1: 1$. Fermentation lasts for 8 days and wine prepared contained $9.4 \%$ alcohol, $0{ }^{\circ} \mathrm{B}, 0.78 \%$ total acidity, $3.9 \mathrm{pH}$ and $15.4 \mathrm{ppm}$ limonin (Table 1). Ethanol efficiency (v/v) was recorded to be 91.8\%. After the fermentation, wine was clarified by racking in bottles that were finally $\mathrm{N} 2$ sparged and stored at $15{ }^{\circ} \mathrm{C}$.

Table 1: Fermentation of kinnow juice ameloriated date juice by MTCC 11815.

\begin{tabular}{|c|c|c|c|c|c|c|c|}
\hline & Brix $\left({ }^{\circ} \mathbf{B}\right)$ & Ethanol \% (v/v) & Total sugars (g/100ml) & $\begin{array}{c}\text { Reducing sugars } \\
\mathbf{( g / 1 0 0 m l )}\end{array}$ & $\begin{array}{c}\text { Total Acidity \% } \\
\mathbf{( v / v )}\end{array}$ & $\begin{array}{c}\mathbf{p H} \\
\mathbf{B r i x}-\mathbf{A c i d} \\
\mathbf{r a t i o}\end{array}$ \\
\hline Initial & 20 & 0 & 19.58 & 12.61 & 0.65 & 5.2 & 30.76 \\
\hline Final & 0 & 9.4 & 0.05 & 0.099 & 0.78 & \\
\hline CD (5\%) & & & & & 3.9 & \\
\hline
\end{tabular}

*Initial brix (Total sugars $(\mathrm{g} / 100 \mathrm{ml})$, Reducing sugars $(\mathrm{g} / 100 \mathrm{ml}))-20 \pm 1.1^{\circ} \mathrm{B}$

Volume of extracted juice $(\mathrm{ml})$

Juice recovery $(\%)=$ 100

Weight of kinnow taken $(\mathrm{kg})$ 


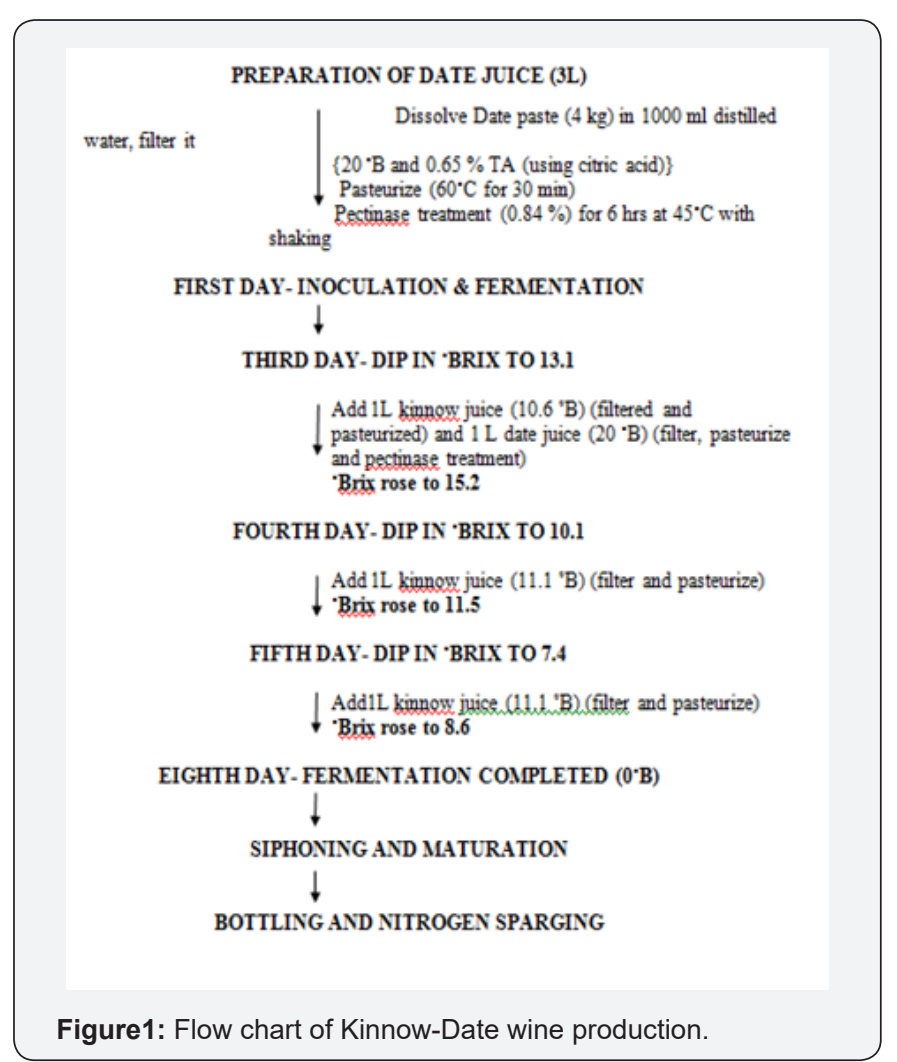

Post juice extraction of kinnow, large quantities of agroindustrial wastes such as peels, seeds, pulp and other residues are produced that are rich in valuable nutrients and biomass, which may be converted into value-added products. In particular, peels have a comparatively higher concentration of phenolic compounds and essential oils and thus have more antioxidant potential than fruit pulps [6]. Kinnow seeds (1500-2000ppm) and peel $(60-80 \mathrm{ppm})$ are also rich in limonin which is a potential bioactive compound with tremendous health promoting properties. It exhibits a significant biological activity, including anticancer, cholesterol-lowering, antioxidant, anti-inflammatory and antiviral activities [7,8] thus possessing a number of potential applications in pharmaceuticals and cosmaceuticals. Although limonin is of great use in research and health products, it is quite expensive as $10 \mathrm{mg}$ of limonin (analytical standard) from Sigma-Aldrich costs Rs 43000 (approx.). Keeping this in mind, the research was conducted to find an alternate of chemically procured limonin. Since, it is highest in seeds, followed by peels and lowest in juice of citrus [9] seeds of the citrus fruits were used to extract limonin. On an average 20-25 seeds are present in a single piece of kinnow fruit which can be used for limonin production. In recent years, several extraction methods for limonin extraction from kinnow seeds have been investigated, for instance supercritical carbon dioxide (SC-CO2), hydrotropic extraction $[10,11]$, extraction using organic solvents and alkaline extraction [12]. Under this research kinnow seeds were washed thoroughly to remove the pulp and air dried. Weight of the dried seeds was taken and seeds were ground into a fine powder. Limonin was extracted from the seed powder using petroleum ether followed by chloroform. Limonin obtained in the chloroform was concentrated into a precipitate in a vacuum evaporator. Limonin and concentration obtained was estimated using HPLC and was found to be $0.74 \mathrm{mg} / \mathrm{g}$ seeds. Premi et al. [9] reported that the peel of kinnow Mandarin seeds contain limonin about $9.50 \mathrm{mg} / \mathrm{g}$. Bilal et al. [13] also determined limonin content in different citrus cultivars and reported limonin $99.62 \mu \mathrm{g} / \mathrm{ml}$ in kinnow seeds. It suggests that limonin, a priced chemical, can be extracted from kinnow seeds in an amount required for its pharmacological and clinical properties [13-15]. Therefore in our ongoing study on fermentative processing of kinnow for kinnow wine preparation, limonin was extracted from otherwise waste kinnow seeds. This will improve the economic status of kinnow growers in the state.

\section{References}

1. Bhardwaj R L, Mukherjee S (2011) Effects of fruit juice blending ratios on kinnow juice preservation at ambient storage condition. Afr J Food Sci 5(5): 281-286.

2. Careina S Stockley (2011) Handbook of Enology. Asia Tech Publishers Inc., New Delhi, India p. 146-208.

3. Patil A B, Matapathi S S, Jones Nirmalnath P, Sheik M K and Patil S (2005). Screening of pomegranate cultivars for wine production. Beverage and Food World 56-58.

4. Khandelwal P, Kumar V, Das N, Tyagi S Mohan (2006) Development of a process for preparation of pure and blended kinnow-wine without debittering kinnow mandarin juice development of a process for preparation of pure \& blended kinnow-wine without debittering kinnow mandarin juice. J Food Safety 8: 24-9.

5. Joshi V K, Kumar V and Kumar A (2012) Physico-chemical and sensory evaluation of wines from different citrus fruits of Himachal Pradesh. Intl J of Food Ferment Technol 2(2): 145-48.

6. Deng G F, Shen C, Xu X R, Kuang R D, Guo Y J, et al. (2012) Potential of fruit wastes as natural resources of bioactive compounds. Int J Mol Sci 13(7): 8308-8323.

7. Miller EG, Porter JL, Binnie WH, Guo IY, Hasegawa S (2004) Further studies on the anticancer activity of citrus limonoids. J of Agri and Food 52: 4908-4912.

8. Manners G D (2007) Citrus limonoids: Analysis, bioactivity, and biomedical prospects. J of Agri and Food Chem 55(21): 8285-8294.

9. Premi B R, Lal B B and Joshi V K (1995) Debittering of kinnow juice with amberlite XAD-16 resin. Indian Food Packer 9-17.

10. Yu J, Dandekar D V, Toledo R T, Singh R K and Patil B S (2007) Supercritical fluid extraction of limonoids and naringin from grapefruit (Citrus paradisi Macf.) seeds. Food Chemistry 105: $\quad 1026$ 1031.

11. Dandekar DV, Jayaprakasha GK, Patil B S (2008) Hydrotropic extraction of bioactive limonin from sour orange (Citrus aurantium L.) seeds. Food Chemistry 109: 515-520.

12. Liu C, Liu J, Rong Y, Liang N and Rong L (2012) Aqueous extraction of limonin from Citrus reticulate Blanco. Czech J Food Sci 4: 364-68.

13. Bilal H, Akram W, Hassan S Ali, Sahar S, Iqbal M Munir (2013) Determination of limonin and nomilin contents in different citrus cultivars using high performance liquid chromatography. Pak J Sci Ind Res B Biol Sci 56 (1): 36-40.

14. PHM (2015-16) Punjab Horticulture Mission

15. Premi BR, Hegde RN (1998) Solution to bitterness in citrus juice. Agriculture tribune. 
This work is licensed under Creative Commons Attribution 4.0 License

DOI: $10.19080 /$ CTBEB.2017.04.555637
Your next submission with Juniper Publishers will reach you the below assets

- Quality Editorial service

- Swift Peer Review

- Reprints availability

- E-prints Service

- Manuscript Podcast for convenient understanding

- Global attainment for your research

- Manuscript accessibility in different formats

( Pdf, E-pub, Full Text, Audio)

- Unceasing customer service

Track the below URL for one-step submission https://juniperpublishers.com/online-submission.php 